\title{
Comparison between Duncan and Chang's EB Model and the Generalized Plasticity Model in the Analysis of a High Earth-Rockfill Dam
}

\author{
Weixin Dong, Liming Hu, Yu Zhen Yu, and He Lv \\ State Key Laboratory of Hydro-Science and Engineering, Department of Hydraulic Engineering, Tsinghua University, \\ Beijing 100084, China
}

Correspondence should be addressed to Yu Zhen Yu; yuyuzhen@tsinghua.edu.cn

Received 4 June 2013; Revised 19 August 2013; Accepted 20 August 2013

Academic Editor: Fayun Liang

Copyright (C) 2013 Weixin Dong et al. This is an open access article distributed under the Creative Commons Attribution License, which permits unrestricted use, distribution, and reproduction in any medium, provided the original work is properly cited.

\begin{abstract}
Nonlinear elastic model and elastoplastic model are two main kinds of constitutive models of soil, which are widely used in the numerical analyses of soil structure. In this study, Duncan and Chang's EB model and the generalized plasticity model proposed by Pastor, Zienkiewicz, and Chan was discussed and applied to describe the stress-strain relationship of rockfill materials. The two models were validated using the results of triaxial shear tests under different confining pressures. The comparisons between the fittings of models and test data showed that the modified generalized plasticity model is capable of simulating the mechanical behaviours of rockfill materials. The modified generalized plasticity model was implemented into a finite element code to carry out static analyses of a high earth-rockfill dam in China. Nonlinear elastic analyses were also performed with Duncan and Chang's EB model in the same program framework. The comparisons of FEM results and in situ monitoring data showed that the modified PZ-III model can give a better description of deformation of the earth-rockfill dam than Duncan and Chang's EB model.
\end{abstract}

\section{Introduction}

The constitutive model of soil is the keystone in the finite element analyses of geotechnical structures. A suitable constitutive model can simulate the stress-strain relationships of soils under static or dynamic conditions. Numerical analysis, especially for finite element method incorporated with soil constitutive models, has played a very important role in geotechnical analyses which always include complex boundary conditions, nonlinearity of material, and geometry [1].

Biot presented the famous three-dimensional consolidation theory based on the effective stress theory, equilibrium equation, and continuity condition [2]. However, it is quite difficult to give the theoretical solution of Biot's consolidation theory except for few simple problems. Up to the 1960s, with the rapid development of electronic computer and constitutive models of soils, Biot's consolidation theory was successfully implemented in finite element codes to study the behavior of geotechnical structures $[3,4]$. So far, thousands of constitutive models have been proposed, which can be mainly grouped in two categories: nonlinear elastic models and elastoplastic models.

For nonlinear elastic model, the nonlinear characteristic of soil stress-strain relationship is considered by sectionalized linearization. A typical nonlinear elastic model is Duncan and Chang's Model $[5,6]$, which has been widely used in the numerical analyses of earth-rockfill dams, as the model parameters are quite easy to be determined from conventional triaxial tests. And, a lot of experience of application has been accumulated for this model. However, nonlinear elastic models also have some inherent limitations to represent the stress-strain characteristics of soils, such as shear-induced dilatancy and stress path dependency.

Elastoplastic models would be very adequate in describing many key features of soils. Classical elastoplastic models are based on the plastic incremental theory composed of yield condition, flow rule, and hardening law. In the 1950s, Drucker et al. (1957) [7] suggested a cap yield surface controlled by volumetric strain. Roscoe et al. [8,9] proposed the concepts of critical state line and state boundary surface, and then 
they built the Original Cam Clay Model based on triaxial tests. Burland [10] suggested a different energy equation and then established the Modified Cam Clay Model. Since the establishment of Cam Clay Model, some other types of elastoplastic constitutive models have also achieved great development [11-18]. Among these models, the generalized plasticity model $[16,19,20]$ can simulate the static and dynamic mechanical behaviors of clays and sands. This model is very flexible and convenient to extend, as the complicated yield or plastic potential surfaces need not to be specified explicitly. And the model has been used successfully in the static or dynamic analyses of some geotechnical structures [21-24]. Furthermore, based on the framework of generalized plasticity theory [16], some limitations of the original model have been solved [25-28], such as pressure dependency, densification under cyclic loading. The details of the generalized plasticity theory and the original and proposed modified Pastor-Zienkiewicz-Chan's models will be introduced in the sections below.

However, little experience has as yet been accumulated in applying the generalized plasticity model to the simulation of rockfill materials. And we know that rockfill material is quite different from sands in mechanical properties [29-31]. The rockfill material has large particle size and sharp edges and corners, which can result in remarkable particle breakage and change the shear-induced dilation $[32,33]$. On the other hand, though the generalized plasticity model has gained great success in the modeling of soils, the application of this model in the large-scale finite element analyses of earth dams was less reported.

In this study, the original generalized plasticity model was modified to consider the stress-strain relationships of rockfill materials, as most of previous studies focused on sands and clays. Then, based on conventional triaxial test data, the model parameters for dam materials of the Nuozhadu high earth-rockfill dam in Southwest China are determined. Finally, the static simulation of this dam is carried out by using a finite element code incorporating with Duncan and Chang's EB model and the modified generalize plasticity model. The comparison of numerical results and in situ monitoring data illustrates the advantages of modified generalized plasticity model in the simulation of earth-rockfill dams.

\section{Constitutive Model Descriptions}

Two constitutive models of soils were used in the finite element analyses. One is the Duncan and Chang's EB model belonging to nonlinear elastic model, the other one is the generalized plasticity model.

2.1. Duncan and Chang's Model. Duncan and Chang's model [5] is a nonlinear elastic model, which has been widely used in the geotechnical engineering, especially in the numerical analyses of earth dams. It is attributed to Kondner [34] who proposed the hyperbolic stress-strain function below to describe the deviatoric stress-axial strain curve obtained from triaxial tests.
Consider

$$
\sigma_{1}-\sigma_{3}=\frac{\varepsilon_{1}}{a+b \varepsilon_{1}}
$$

in which $a$ and $b$ are model constants.

In this constitutive model, the tangential Young's modulus $E_{t}$ and tangential bulk modulus $B_{t}$ are used to simulate the nonlinear elastic response of soils, which are assumed to be

$$
\begin{gathered}
E_{t}=K P_{a}\left(\frac{\sigma_{3}}{P_{a}}\right)^{n}\left(1-R_{f} S_{l}\right)^{2}, \\
B_{t}=K_{b} P_{a}\left(\frac{\sigma_{3}}{P_{a}}\right)^{m},
\end{gathered}
$$

where $P_{a}$ is the atmospheric pressure, $K$ and $K_{b}$ are modulus numbers, $n$ and $m$ are exponents determining the rate of variation of moduli with confining pressure, and $R_{f}$ is the failure ratio with a invariable value less than 1 .

The Mohr-Coulomb failure criterion is adopted in the model, and $S_{l}$ is a factor defined as shear stress level given by

$$
S_{l}=\frac{(1-\sin \phi)\left(\sigma_{1}-\sigma_{3}\right)}{2 c \cdot \cos \phi+2 \sigma_{3} \cdot \sin \phi}
$$

In the unloading and reloading stage, the tangential Young's modulus is defined as

$$
E_{u r}=K_{u r} P_{a}\left(\frac{\sigma_{3}}{P_{a}}\right)^{n} .
$$

So far, the model has 8 parameters, $c, \varphi, K, K_{u r}, n, R_{f}$, $K_{b}, m$. These parameters can be determined with a set of conventional triaxial tests.

In general, a curved Mohr-Coulomb failure envelop is adopted by setting $c=0$ and letting $\varphi$ vary with confining pressure according to

$$
\varphi=\varphi_{0}-\Delta \varphi \log \left(\frac{\sigma_{3}}{P_{a}}\right) .
$$

Then parameters $c$ and $\varphi$ are replaced by $\varphi_{0}$ and $\Delta \varphi$.

Although Duncan and Chang's EB constitutive model is quite simple, it has gained significant success in geotechnical engineering. On one hand, it is easy to obtain the model parameters; on the other hand, much experience has been accumulated. Nevertheless, it cannot incorporate dilatancy which has an important influence in the mechanical behavior of soils. And furthermore, it can only consider unloading process in a crude way.

\subsection{Generalized Plasticity Theory and Its Original Constitutive Model}

2.2.1. Basic Theory. The generalized plasticity theory was proposed by Zienkiewicz and Mroz (1984) [16] to model the behaviors of sand under monotonic and cyclic loading. The 
key futures of this theory are that neither yield surface nor plastic potential surface needs to be defined explicitly, and consistency law is not required to determine plastic modulus. In the theory, the total strain increment is divided into elastic and plastic components.

Consider

$$
d \varepsilon=d \varepsilon^{e}+d \varepsilon^{p}
$$

where $d \varepsilon^{e}$ and $d \varepsilon^{p}=$ elastic and plastic strain increments, respectively.

The relationship between strain and stress increments is expressed as

$$
d \sigma=\mathbf{D}^{e p}: d \varepsilon
$$

where $\mathbf{D}^{e p}$ is the elastoplastic stiffness tensor given as

$$
\mathbf{D}^{e p}=\mathbf{D}^{e}-\frac{\mathbf{D}^{e}: \mathbf{n}_{g L / U}: \mathbf{n}^{T}: \mathbf{D}^{e}}{H_{L / U}+\mathbf{n}^{T}: \mathbf{D}^{e}: \mathbf{n}_{g L / U}},
$$

where $\mathbf{D}^{e}, \mathbf{n}_{g L / U}, \mathbf{n}$, and $H_{L / U}$ are elastic stiffness tensor, plastic flow direction vector, loading direction vector, and plastic modulus under loading or unloading conditions, respectively.

The loading direction vector $\mathbf{n}$ is used to judge the loading and unloading conditions:

$$
\begin{gathered}
d \sigma_{e}^{T} \cdot \mathbf{n}>0 \quad \text { loading, } \\
d \sigma_{e}^{T} \cdot \mathbf{n}=0 \quad \text { neutral loading, } \\
d \sigma_{e}^{T} \cdot \mathbf{n}<0 \quad \text { unloading. }
\end{gathered}
$$

Then, the elastoplastic stiffness tensor $\mathbf{D}^{e p}$ can be obtained corresponding to the loading and unloading conditions.

In the framework of generalized plasticity theory, all the components of the elastoplastic constitutive matrix are determined by the current state of stress and loading/unloading condition.

2.2.2. Pastor-Zienkiewicz-Chan Model. This model was presented by Pastor et al. [19]. The relationships between elastic volumetric and shear strain increments and stress increments are defined as

$$
d p^{\prime}=K_{e v} d \varepsilon_{v}^{e}, \quad d q=3 G_{e s} d \varepsilon_{s}^{e},
$$

where $K_{e v}, G_{e s}$ are tangential bulk and shear moduli, respectively, and they are assumed to be

$$
K_{e v}=K_{e s o} \frac{p^{\prime}}{p_{o}}, \quad G_{e s}=G_{e s o} \frac{p^{\prime}}{p_{o}},
$$

where $K_{e s o}, G_{e s o}$, and $p_{o}$ are model parameters.
In order to determine the plastic stiffness tensor, variables $\mathbf{n}_{g L / U}, \mathbf{n}$, and $H_{L / U}$ need to be defined. $\mathbf{n}_{g L / U}$ and $\mathbf{n}$ are expressed as follows:

$$
\begin{gathered}
\mathbf{n}_{g L}=\left(\frac{d_{g}}{\sqrt{1+d_{g}^{2}}}, \frac{1}{\sqrt{1+d_{g}^{2}}}\right)^{T}, \\
\mathbf{n}=\left(\frac{d_{f}}{\sqrt{1+d_{f}^{2}}}, \frac{1}{\sqrt{1+d_{f}^{2}}}\right)^{T} .
\end{gathered}
$$
follows:

The dilatancy $d_{g}$ and stress ratio $\eta=q / p$ are related as

$$
d_{g}=\frac{d \varepsilon_{v}^{p}}{d \varepsilon_{s}^{p}}=\left(1+\alpha_{g}\right)\left(M_{g}-\eta\right)
$$

And $d_{f}$ has a similar expression as

$$
d_{f}=\left(1+\alpha_{f}\right)\left(M_{f}-\eta\right)
$$

where $\alpha_{f}, \alpha_{g}$ are model parameters and $M_{g} / M_{f}$ is equal to relative density. If $d_{f}=d_{g}$, associated flow rule is used, otherwise nonassociated flow rule is used.

In the case of unloading, the unloading plastic flow direction vector $\mathbf{n}_{g U}$ is defined as

$$
\mathbf{n}_{g U}=\left(-\left|\frac{d_{g}}{\sqrt{1+d_{g}^{2}}}\right|, \frac{1}{\sqrt{1+d_{g}^{2}}}\right)^{T}
$$

The loading plastic modulus $H_{L}$ is proposed as

$$
H_{L}=H_{0} p^{\prime} H_{f}\left(H_{v}+H_{s}\right) H_{D M}
$$

where $H_{f}=\left(1-\eta / \eta_{f}\right)^{4}$ limits the possible state and $\eta_{f}=(1+$ $\left.1 / \alpha_{f}\right) M_{f}, H_{v}=1-\eta / M_{g}$ accounts for phase transformation; $H_{s}=\beta_{0} \beta_{1} \exp \left(-\beta_{0} \xi\right)$ considers soil degradation and $\xi$ is the accumulated plastic shear strain; $H_{D M}=\left(\varsigma_{\mathrm{MAX}} / \varsigma\right)^{\gamma}$ accounts for past history and $\varsigma=p\left[1-\alpha_{f} \eta /\left(1+\alpha_{f}\right) / M_{f}\right]_{f}^{(-1 / \alpha)}$ which is the mobilized stress function; and $H_{0}, \beta_{0}, \beta_{1}, \gamma$ are model parameters.

Under unloading condition, the plastic modulus is defined as

$$
\begin{gathered}
H_{U}=H_{u 0}\left(\frac{M_{g}}{\eta_{u}}\right)^{\gamma_{u}}, \quad \frac{M_{g}}{\eta}>1, \\
H_{U}=H_{u 0}, \quad \frac{M_{g}}{\eta} \leq 1,
\end{gathered}
$$

respectively, where $H_{u 0}, \gamma_{u}$ are model parameters and $\eta_{u}$ is the stress ratio from which unloading takes place. 


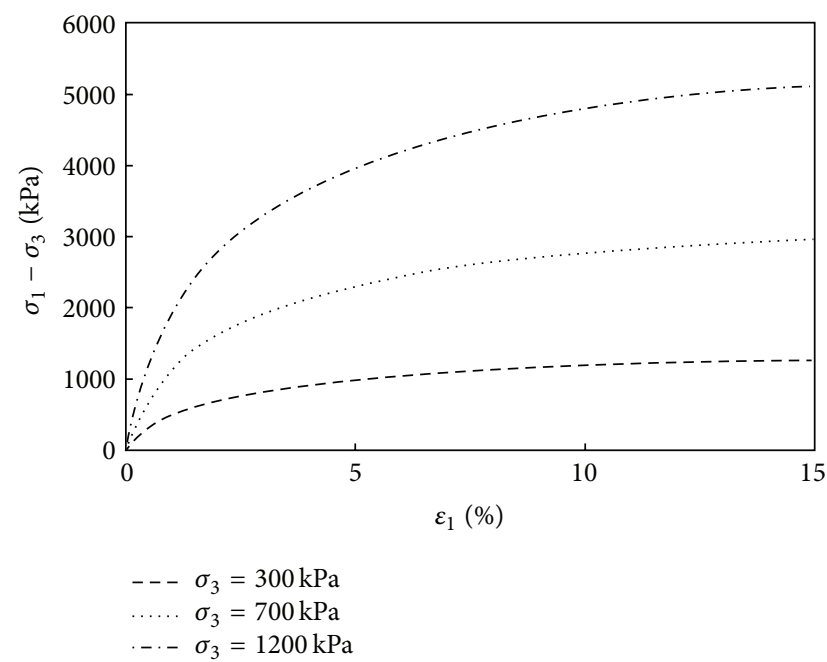

(a)

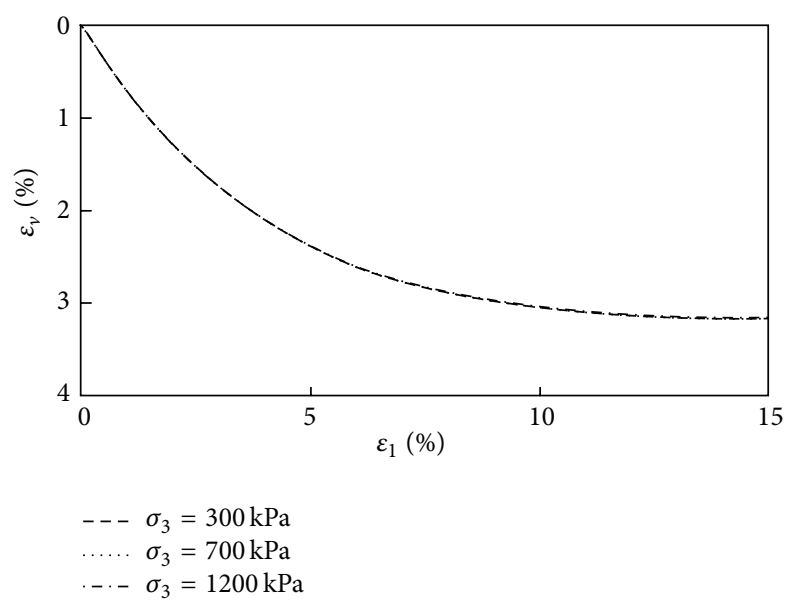

(b)

FIGURE 1: Simulation of stress-strain relationships for Original PZ-III model.

2.2.3. Modified Model. The Pastor-Zienkiewicz-Chan model (PZ-III for short) has gained considerable success in describing the behavior of sands and clays under monotonic and cyclic loadings. But it still has some shortcomings to predict the static or dynamic responds of sands, especially for rockfill materials which are widely used in earth-rockfill dams. The Original PZ-III model has serious limitation in reflecting pressure dependency of soils.

Figure 1 shows the stress-strain relationships of a rockfill material under drained conventional triaxial tests using a set of parameters under different confining pressures, but PZ-III model gives the same $\varepsilon_{1}-\varepsilon_{v}$ curve, where $\varepsilon_{1}, \varepsilon_{v}$ are axial strain and volumetric strain, respectively. As confining pressure ranges from $0 \mathrm{kPa}$ to several $\mathrm{MPa}$ for a rockfill dam with height of 200-300 m, the original PZ-III model cannot be used to describe the mechanical behavior of rockfill dams.

Some relations of the original model are modified to take into account the influence of confining pressure as

$$
\begin{gathered}
K_{e v}=K_{e 0} p_{a}\left(\frac{p^{\prime}}{p_{a}}\right)^{m}, \quad G_{e s}=G_{e 0} p_{a}\left(\frac{p^{\prime}}{p_{a}}\right)^{n}, \\
H_{L}=H_{0} p_{a}\left(\frac{p^{\prime}}{p_{a}}\right)^{m} H_{f}\left(H_{v}+H_{s}\right) H_{D M}
\end{gathered}
$$

where $K_{e 0}$ and $G_{e 0}$ are elastic constants, $m$ and $n$ are model parameters to consider the effect of pressure dependency.

As sand behavior is dependent on densities or void ratio, a state pressure index, $I_{p}$, proposed by Wang et al. [35] was introduced in the PZ-III model and (13) was modified as

$$
d_{g}=\frac{d \varepsilon_{v}^{p}}{d \varepsilon_{s}^{p}}=\left(1+\alpha_{g}\right)\left(M_{g} I_{p}^{m_{p}}-\eta\right)
$$

where $m_{p}$ is a model parameter and $I_{p}=p / p_{c}$ in which $p_{c}$ is the mean pressure at critical state. The critical state line is given by

$$
e_{c}=\Gamma-\lambda \log \left(p_{c}\right)
$$

\section{Nuozhadu Hydropower Project}

Nuozhadu hydropower project is located in the Lancang River which is also named Mekong River in the downstream in Yunnan Province, Southwest China, as shown in Figure 2(a). The installed capacity of the powerstation is $5850 \mathrm{MW}$. The most important part of Nuozhadu hydropower project is the high earth-rockfill dam with a maximum height of $261.5 \mathrm{~m}$, which is the highest one with the same type in China and the fourth highest in the world. The reservoir has a storage capacity of $237.0 \times 10^{8} \mathrm{~m}^{3}$, with the normal storage water level of $812.5 \mathrm{~m}$ and dead water level of $765 \mathrm{~m}$.

Figure 3 shows the material zoning and construction stages of the maximum cross-section. The elevation of the earth core bottom and the crest of the dam are $562.6 \mathrm{~m}$ and $824.1 \mathrm{~m}$, respectively. The dam crest has a longitudinal length of $630 \mathrm{~m}$ with a width of $18 \mathrm{~m}$. The upstream and downstream slopes are at $1.9: 1$ and $1.8: 1$, respectively. The dam body is composed of several different types of materials. The shells of upstream and downstream are composed of decomposed rock materials. Anti-seepage material in the earth core is clay mixed with gravel. Adding gravel to the clay can improve the strength of clay and reduce the arching effect between shells and earth core. The gravel material consists of fresh crushed stone of breccia and granite with a maximum diameter of $150 \mathrm{~mm}$. In addition to these, the fine rockfill and filter materials are filled against the earth core to prevent the fine particle from being washed away.

The dam construction was started in 2008 and was completed at the end of 2012. Figure 2(c) shows the dam 


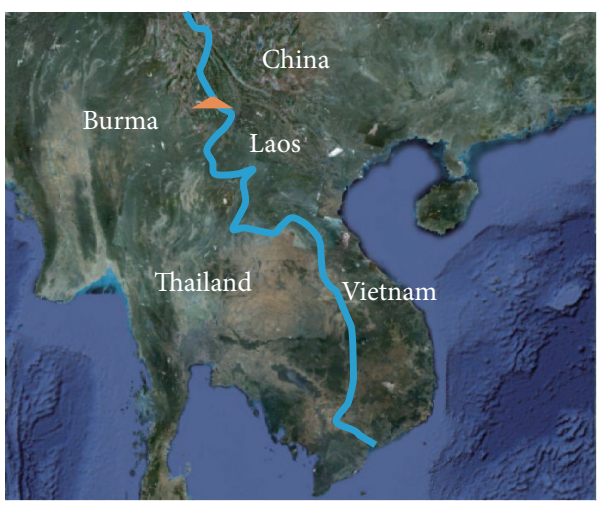

(a)

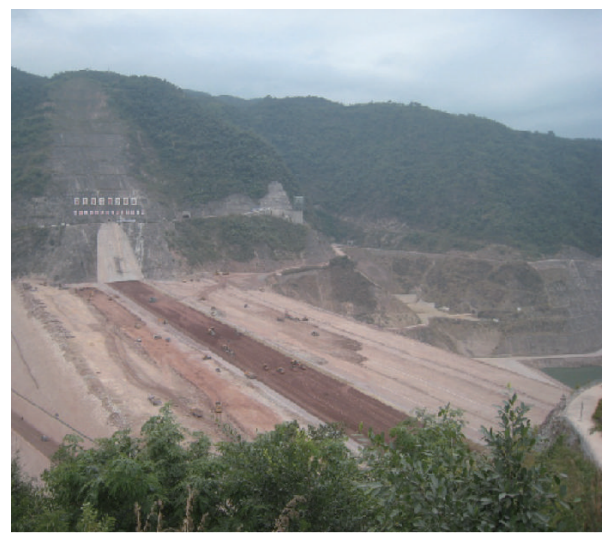

(c)

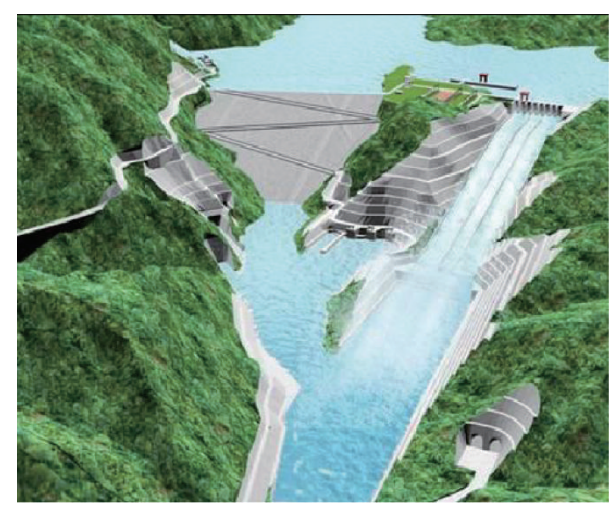

(b)

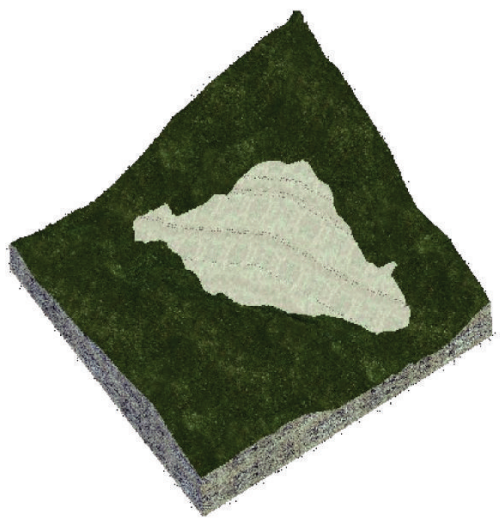

(d)

Figure 2: Nuozhadu dam. (a) Nuozhadu dam location, (b) project blueprint, (c) Nuozhadu dam under construction, and (d) dam site geomorphology.

under construction. Figure 3(b) demonstrates the practical construction process.

\section{Experimental Validation of Model Parameters}

The modified PZ-III model was implemented in a finite element code which has been successfully used to analyze earth dams with Duncan and Chang's EB model and some other constitutive models. A set of triaxial test data was used to make sure that the model has been incorporated into the FEM code accurately.

The proposed generalized plasticity model totally needs 17 parameters. The model parameters used in the computation of the earth-rockfill dam were obtained by fitting the triaxial test results. Drained triaxial tests under different confining pressures were conducted to test the rockfill materials and mixed gravel clay, which are the main parts of the dam body.

Duncan and Chang's EB model parameters are shown in Table 1 and the modified PZ-III model parameters in Table 2. As shown in Figures 4, 5, 6, 7, 8, and 9, the modified PZIII model presents a better ability to simulate the mechanics
TABLE 1: Material parameters of Duncan and Chang's EB model.

\begin{tabular}{lccc}
\hline Material & Rockfill I & Rockfill II & Mixed gravel clay \\
\hline$\varphi /^{\circ}$ & 55.82 & 54.33 & 39.30 \\
$\Delta \varphi /^{\circ}$ & 12.29 & 12.07 & 9.80 \\
$R_{f}$ & 0.73 & 0.74 & 0.77 \\
$K$ & 1450 & 1360 & 520 \\
$K_{b}$ & 550 & 600 & 250 \\
$K_{u r}$ & 2800 & 2500 & 900 \\
$n$ & 0.30 & 0.43 & 0.42 \\
$m$ & 0.13 & 0.08 & 0.25 \\
\hline
\end{tabular}

behavior of rockfill materials and mixed gravel clay, especially for dilatancy. With the reduction of confining pressure, the rockfill materials tend to dilate as the experimental volumetric strain curve shows. Especially for the rockfill materials under low confining pressure, negative volumetric strain rapidly develops after a short stage of volumetric contraction. Due to the intrinsic limitation, Duncan and Chang's EB model cannot simulate the dilatancy which is a crucial feature of rockfill materials. 


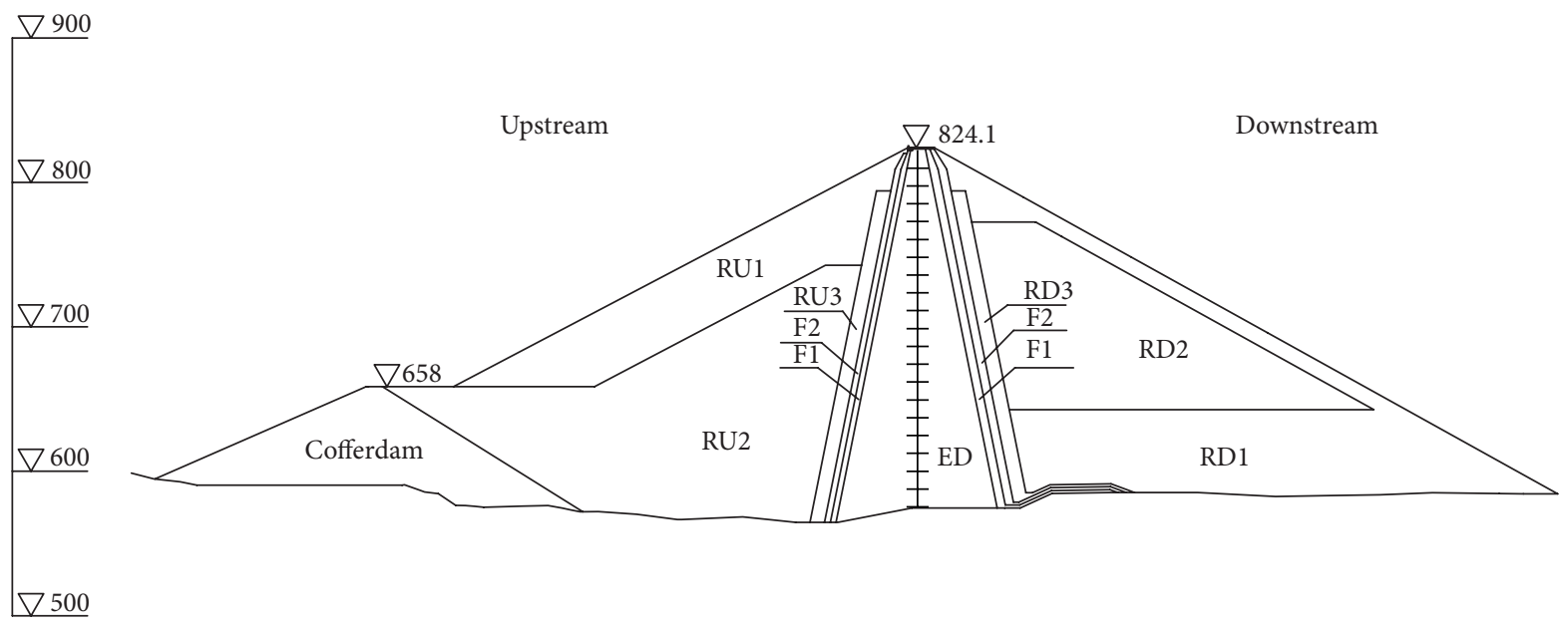

RU1/RD1: upstream/downstream rockfill zone I RU2/RD2: upstream/downstream rockfill zone II RU3/RD3: upstream/downstream fine rockfill
F1/F2: filter material zone I/II

ED: clay mixed gravel

f: electromagnetism type settlement gauges

(a)

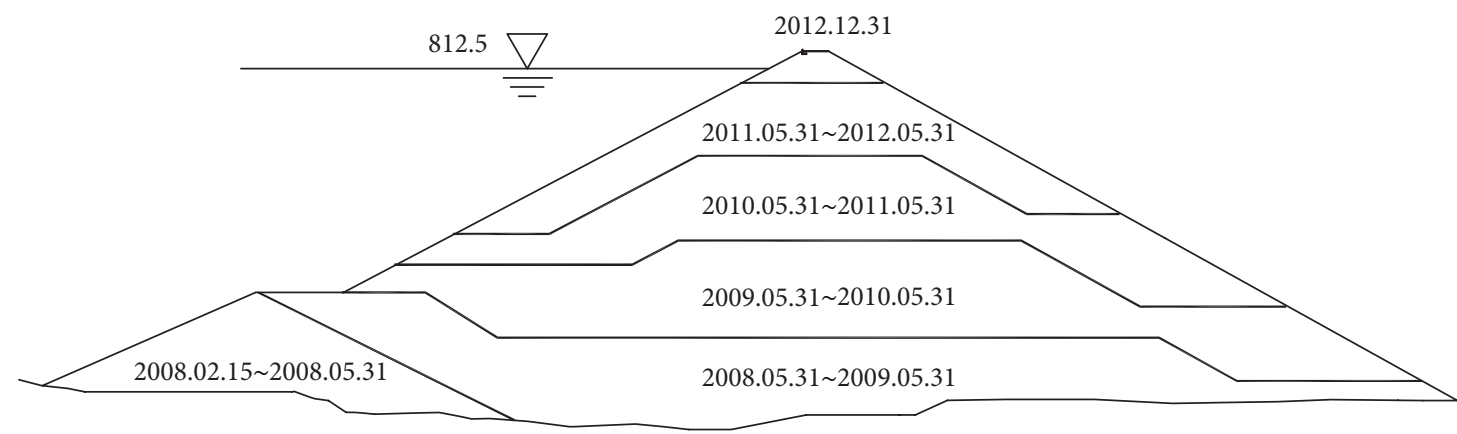

(b)

FIgURE 3: The maximum cross-section. (a) Material zoning and (b) construction stage.

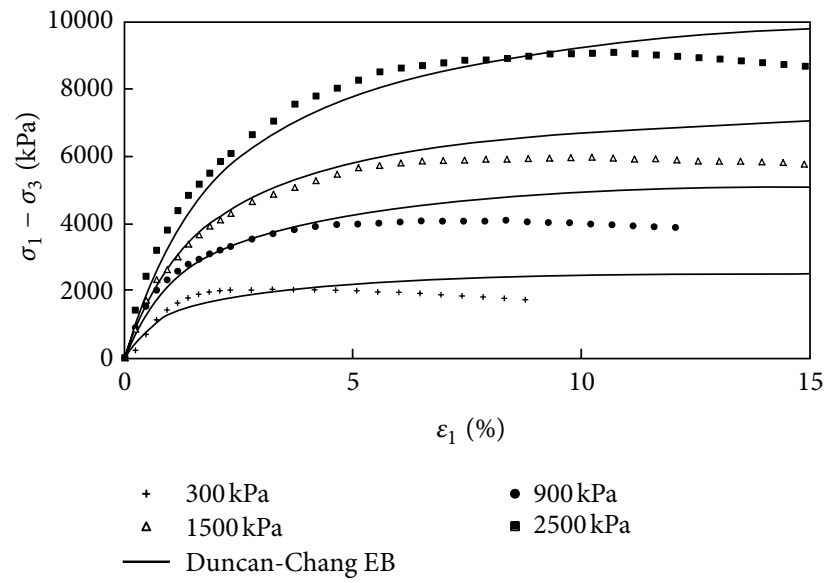

(a)

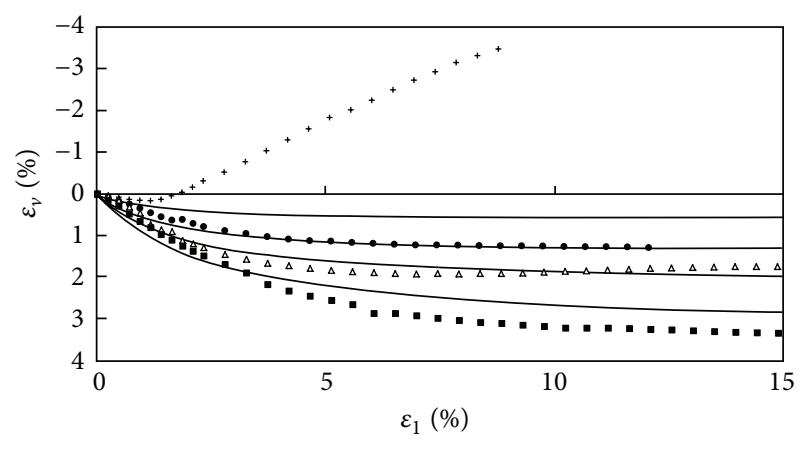

$+\quad 300 \mathrm{kPa}$

$\triangle \quad 1500 \mathrm{kPa}$

— Duncan-Chang EB

(b)

FIgURE 4: Comparison between fittings of Duncan and Chang's EB model and experimental triaxial tests results for rockfill material I. 


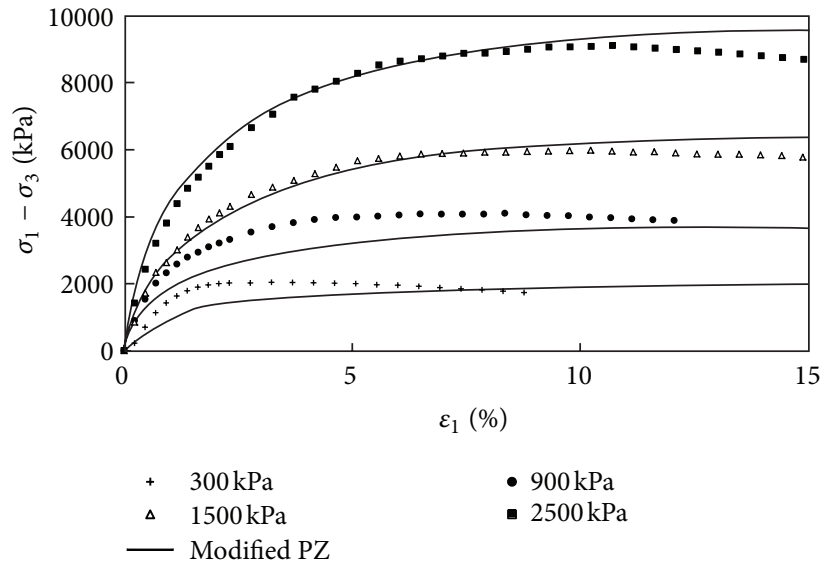

(a)

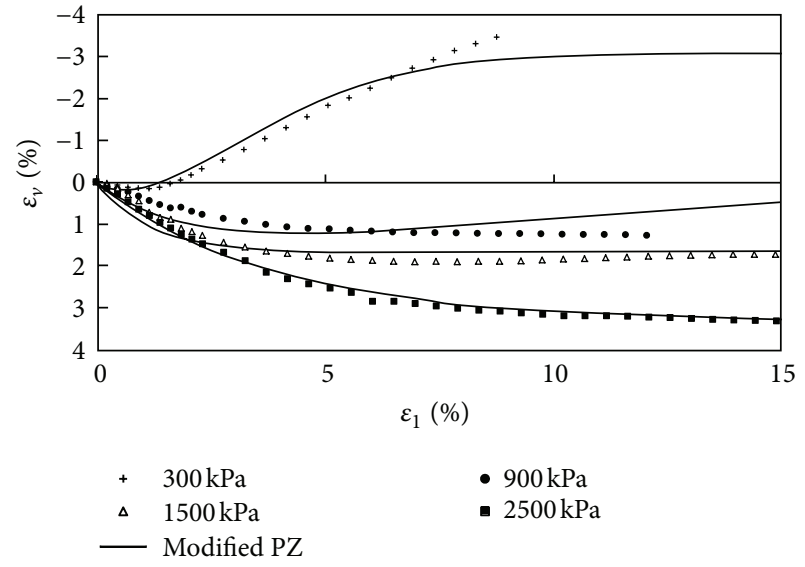

(b)

FIGURE 5: Comparison between fittings of the modified PZ-III model and experimental triaxial tests results for rockfill material I.

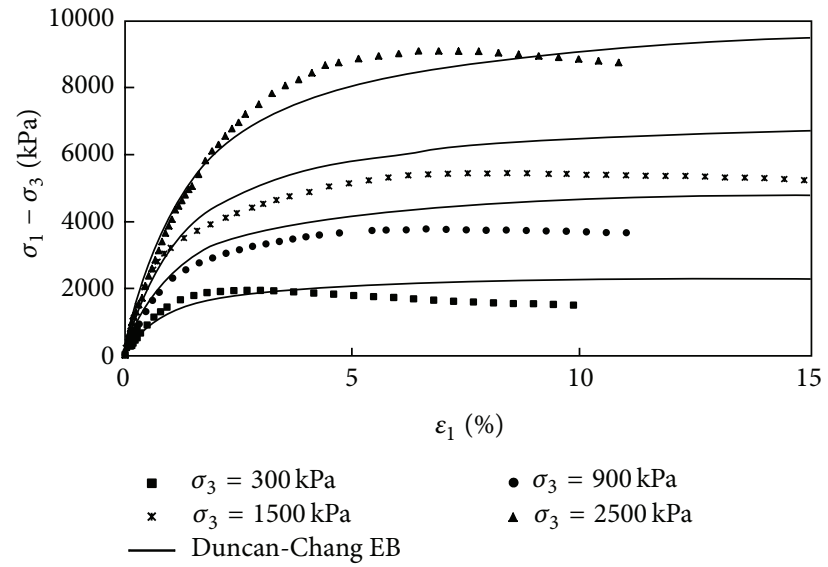

(a)

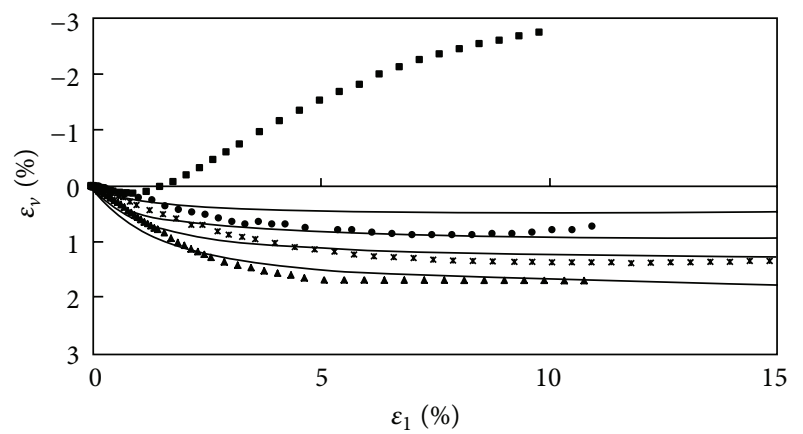

- $\sigma_{3}=300 \mathrm{kPa}$

$\times \sigma_{3}=1500 \mathrm{kPa}$

- $\sigma_{3}=900 \mathrm{kPa}$

^ $\sigma_{3}=2500 \mathrm{kPa}$

— Duncan-Chang EB

(b)

FIGURE 6: Comparison between fittings of Duncan and Chang's EB model and experimental triaxial tests results for rockfill material II.

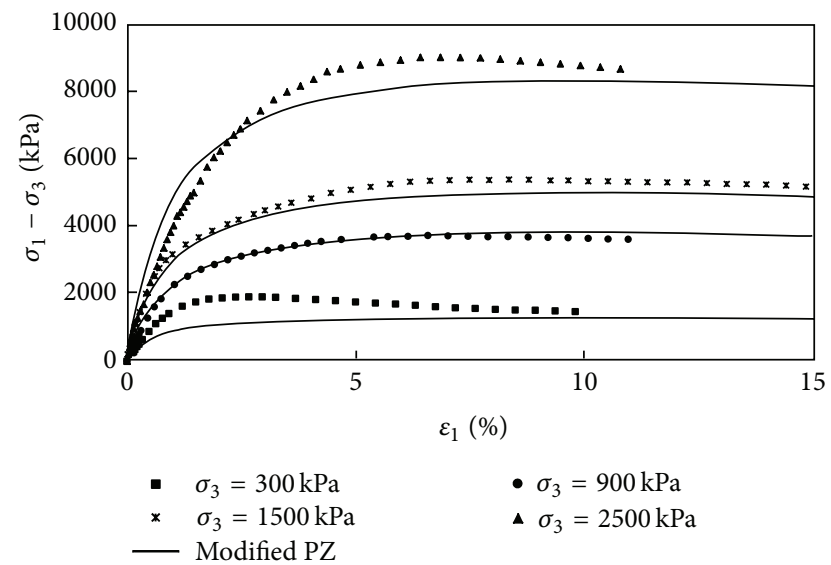

(a)

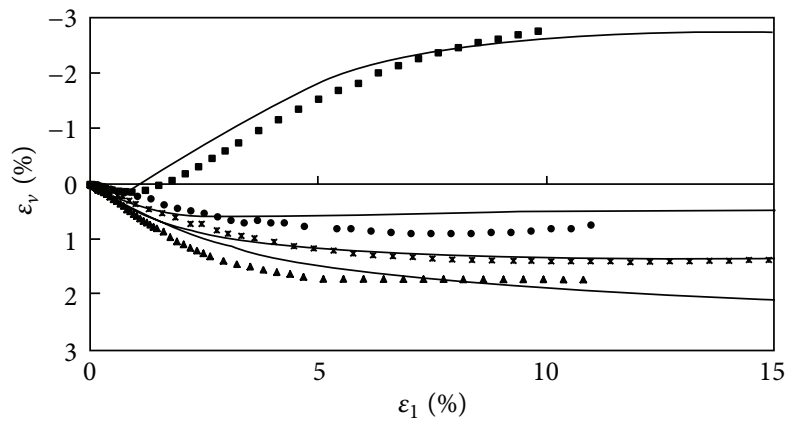

- $\sigma_{3}=300 \mathrm{kPa}$

- $\sigma_{3}=900 \mathrm{kPa}$

$\times \quad \sigma_{3}=1500 \mathrm{kPa}$

\ $\sigma_{3}=2500 \mathrm{kPa}$

- Modified PZ

(b)

FIgURE 7: Comparison between fittings of the modified PZ-III model and experimental triaxial tests results for rockfill material II. 


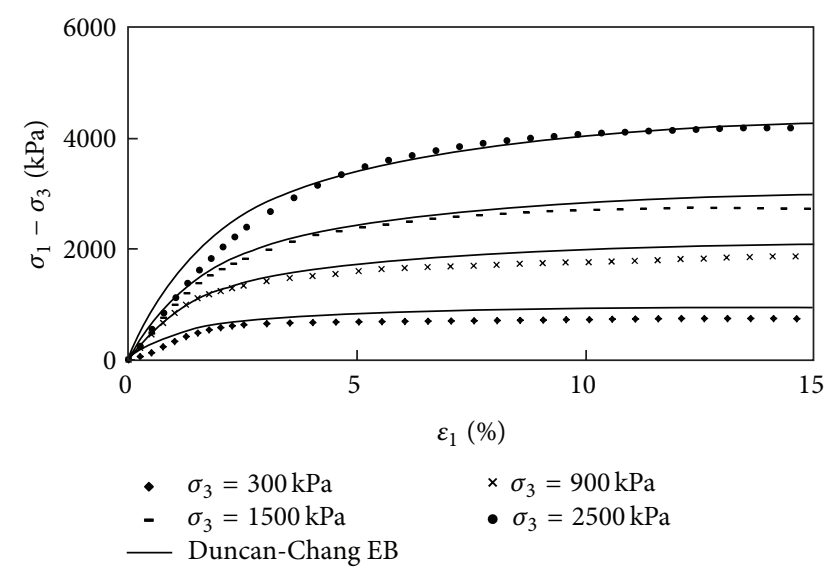

(a)

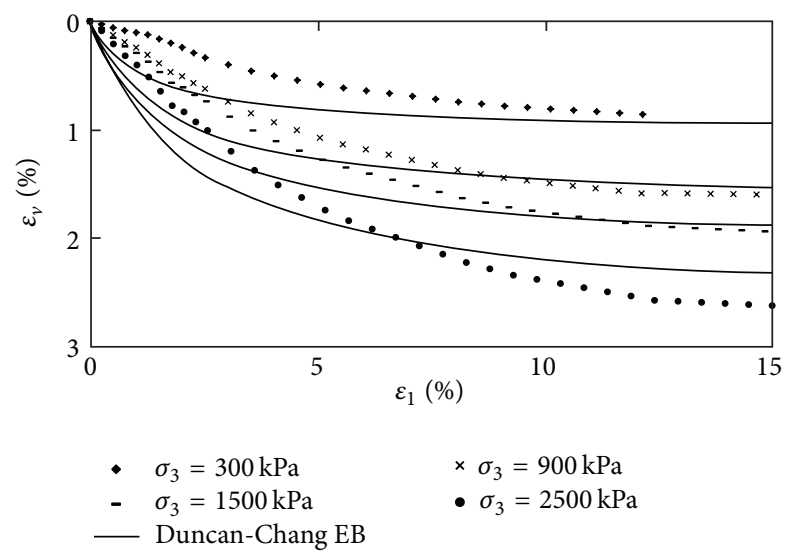

(b)

FIGURE 8: Comparison between fittings of Duncan and Chang's EB model and experimental triaxial tests results for clay.

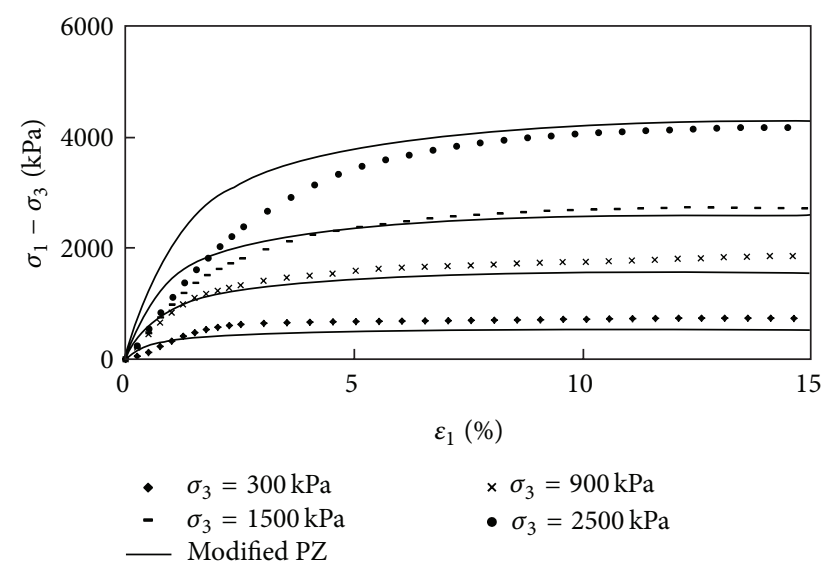

(a)

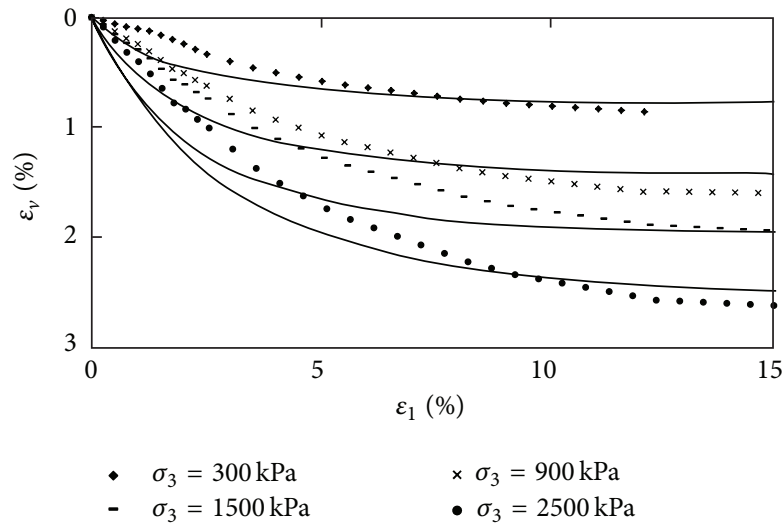

(b)

Figure 9: Comparison between fittings of the modified PZ-III model and experimental triaxial tests results for clay.

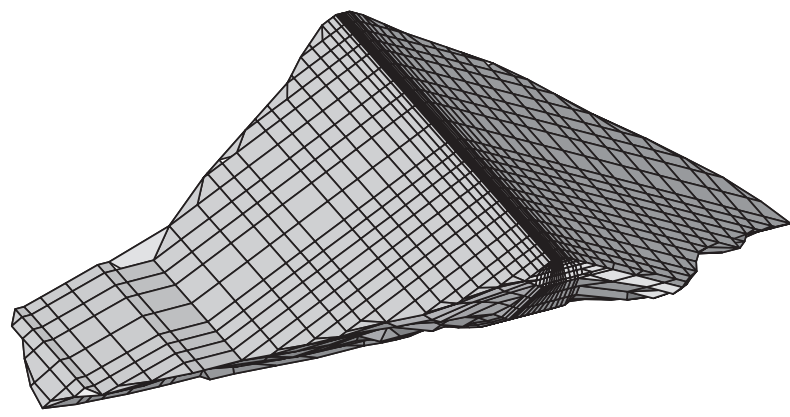

Figure 10: 3D FEM mesh of Nuozhadu dam.

\section{Three-Dimensional Finite Element Analyses}

5.1. Computation Model. The numerical analyses were performed to simulate the performance of the dam during construction and impounding periods with effective stress finite element analysis.
First, the 2D finite element mesh of the maximum crosssection of the dam was discretized according to the material zoning and construction design (see Figure 3 ). Then, the 2D mesh was extended to $3 \mathrm{D}$ mesh in accordance with contour line of the river valley. Figure 10 shows the $3 \mathrm{D}$ mesh of the Nuozhadu dam with 8095 brick and degenerated brick elements and 8340 nodes.

The numerical simulations contain two stages, filling and impounding. During the filling stage, the dam body mainly subjects to body weight. Then, at the end of construction, upstream water level goes up to the normal storage water level. The interaction between pore water and soil skeleton was considered through the whole numerical computation.

\subsection{Results and Analyses}

5.2.1. Numerical Results Analyses. Figures 11 and 12 show the numerical results of finite element analyses with Duncan and Chang's EB model and the modified PZ-III model, respectively. 


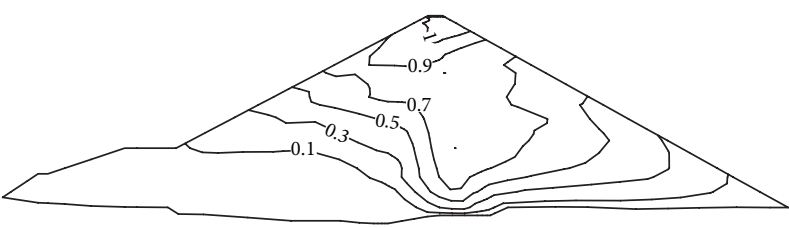

(a)

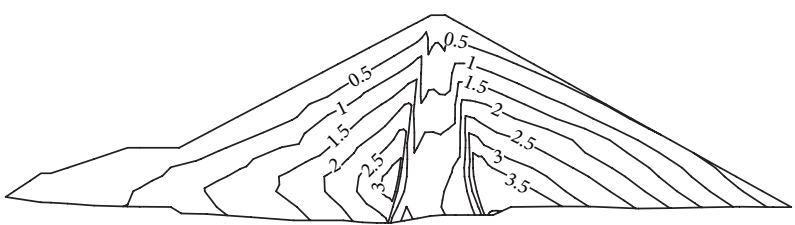

(c)

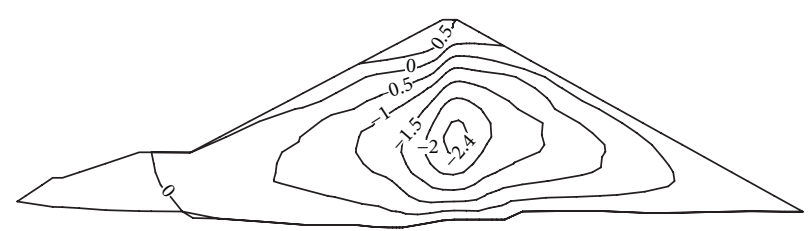

(b)

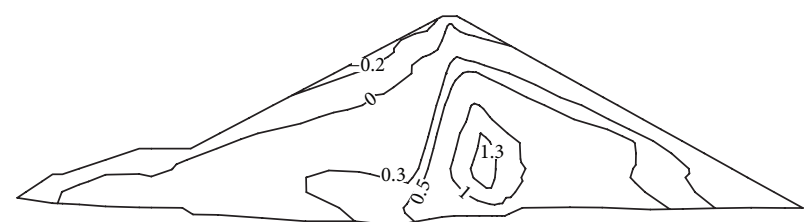

(d)

FIGURE 11: Displacement and stress contour of the maximum section for Duncan and Chang's EB model: (a) displacement along river (m), (b) vertical displacement (m), (c) major principle stress (MPa), and (d) minor principle stress (MPa).

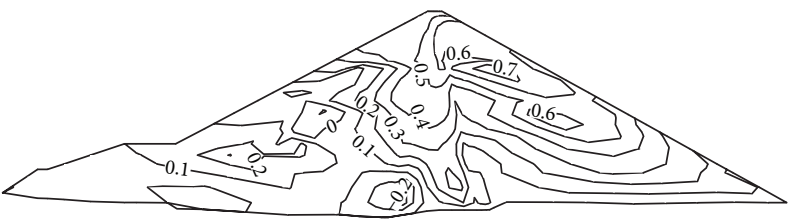

(a)

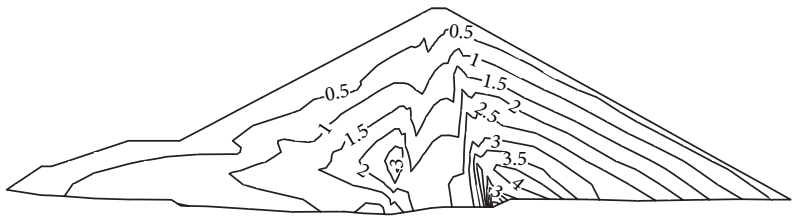

(c)

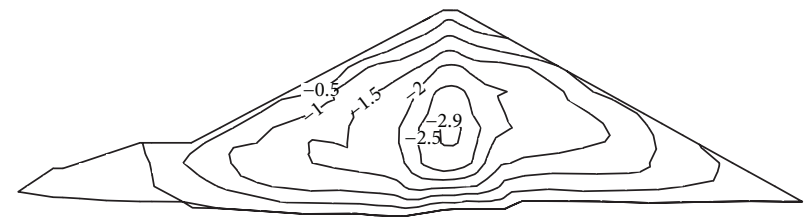

(b)

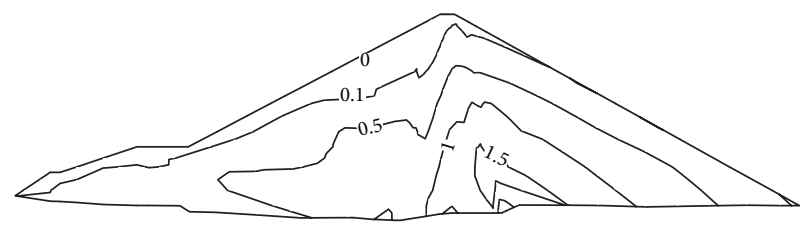

(d)

FiguRE 12: Displacement and stress contour of the maximum section for the modified PZ-III model: (a) displacement along river (m), (b) vertical displacement $(\mathrm{m}),(\mathrm{c})$ major principle stress $(\mathrm{MPa})$, and (d) minor principle stress (MPa).

Through the comparison and analysis of the numerical results (Figures 11 and 12), we can find some similarities and differences for these two models.

On one hand, we can see many similar places in the distributions of displacements and stresses.

(1) After the reservoir impounding, due to the huge water pressure on upstream dam, horizontal displacement develops toward the downstream, and the largest displacement is about $1.05 \mathrm{~m}$ for $\mathrm{EB}$ model and $0.74 \mathrm{~m}$ for modified PZ-III model.

(2) The maximum settlement occurs in the middle of core wall due to lower modulus of clayey soil.

(3) Because of the tremendous differences of modulus between rockfill material and clayey soil, there exists obvious arching effect in the core wall.

(4) Effective stress in upstream shell is less than the downstream shell due to the water pressure in the upstream shell.

On the other hand, some differences also exist, which illustrate the advantages of modified PZ-III model.
(1) After the reservoir is impounded, upward displacement as large as $0.7 \mathrm{~m}$ (see Figure 11(b)) develops on the upstream shell near dam crest for EB model and nearly $0 \mathrm{~m}$ for modified PZ-III model (see Figure 12(b)). In fact, monitoring data of practical engineering projects shows that no large upward displacement happened after impounding. This is due to its weakness of EB model to distinguish the loading and unloading condition during the water impounding.

(2) In the distribution of minor principle stress (Figures $11(\mathrm{~d})$ and $12(\mathrm{~d})$ ), negative stress (i.e., tensile stress) occurs in the upstream shell for EB model, whereas very little tensile stress exists for modified PZ-III model. As we know, rockfill material is a typical kind of cohesionless coarse-grained soil, which means that it has no tensile strength. Therefore, the existence of large area of tensile stress in the upstream shell is unreasonable.

5.2.2. Comparison between Numerical and In Situ Monitoring Data. Settlement is a key indicator to assess the safety of an 


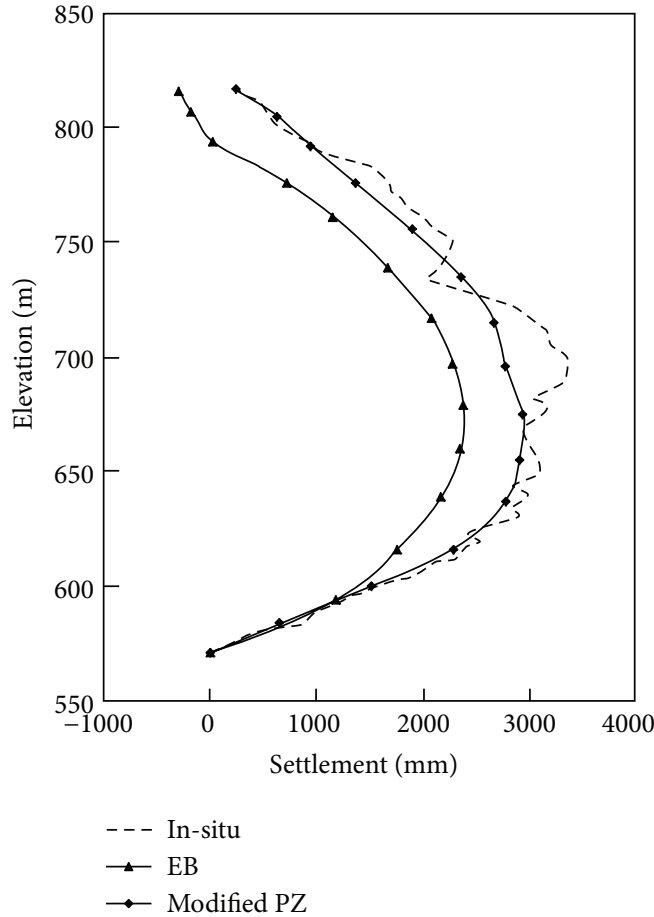

FIGURE 13: Comparison between in situ monitoring settlement and FEM results.

TABLE 2: Material parameters of the modified PZ-III model.

\begin{tabular}{lccc}
\hline Material & Rockfill I & Rockfill II & Mixed gravel clay \\
\hline$K_{0}$ & 500 & 1000 & 300 \\
$G_{0}$ & 1500 & 3000 & 900 \\
$m$ & 0.50 & 0.50 & 0.50 \\
$n$ & 0.50 & 0.50 & 0.50 \\
$\alpha_{f}$ & 0.45 & 0.45 & 0.45 \\
$\alpha_{g}$ & 0.45 & 0.45 & 0.45 \\
$M_{f c}$ & 1.05 & 0.90 & 0.60 \\
$M_{g c}$ & 1.60 & 1.35 & 1.10 \\
$\beta_{0}$ & 0.00 & 0.00 & 0.00 \\
$\beta_{1}$ & 0.00 & 0.00 & 0.00 \\
$\Gamma$ & 0.34 & 0.31 & 0.34 \\
$\lambda$ & 0.10 & 0.09 & 0.03 \\
$m_{p}$ & 0.35 & 0.40 & 0.0 \\
$H_{0}$ & 800 & 1200 & 900 \\
$\gamma$ & 5 & 5 & 5 \\
$\gamma_{u}$ & 5 & 5 & 5 \\
$H_{u 0} / \mathrm{MPa}$ & 9 & 9 & 10
\end{tabular}

earth dam. Figures 13 and 14 show the in situ monitoring data and FEM results of settlement in the maximum cross-section. The in situ data were obtained from electromagnetism type settlement gauges which were embedded during construction in the dam (as shown in Figure 3(a)). Through the comparisons of in situ monitoring and numerical results, we can see that the modified PZ-III model gave a better prediction than the EB model. However, as deformation induced by wetting

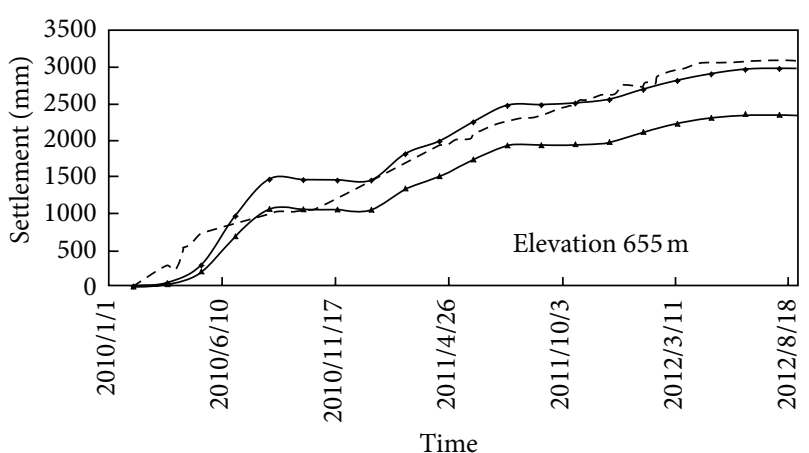

(a)

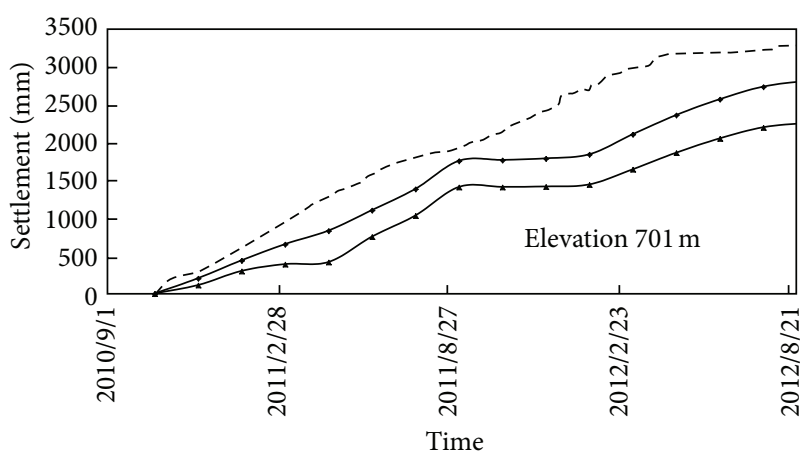

(b)

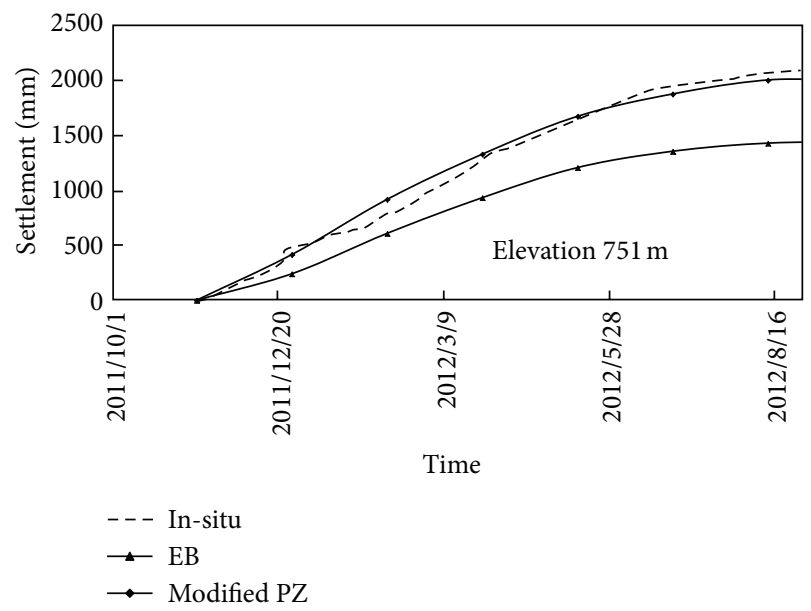

(c)

FIGURE 14: Comparison between in situ monitoring settlement and FEM results.

of rockfill materials was not considered, the FEM result of settlement was below than the in situ monitoring data.

As an elastoplastic model, the PZ-III model is capable of representing the mechanical behavior of soils better than nonlinear elastic model such as Duncan and Chang's EB model. And the above finite element analyses also proved it.

\section{Conclusions}

This paper presents a modified PZ-III model based on the generalized theory and original Pastor-Zienkiewicz-Chan 
model to simulate the stress-strain relationship of rockfill materials.

Triaxial test results of the filling materials of Nuozhadu dam were used to validate the proposed model and determine the model parameters of Duncan and Chang's EB model and the modified PZ-III model, respectively. The simulations of triaxial stress-strain response show that the modified PZIII model is capable of representing the key features of cohesionless soil, such as nonlinearity, dilatancy, and pressure dependency.

The proposed model has been incorporated into a finite element code to simulate the static response of a high earthrockfill dam in China. The results were compared with those of Duncan and Chang's EB model. The two set of results have both similarities and differences and the differences illustrate the advantages of the modified PZ-III model. The comparisons of FEM results, and in situ monitoring data showed that the modified PZ-III model can give a better description of deformation of the earth-rockfill dam than Duncan and Chang's EB model.

\section{Acknowledgments}

This work was supported by the National Nature Science Foundation of China (51179092) and the State Key Laboratory of Hydroscience and Engineering Project (2012-KY-02 and 2013-KY-4).

\section{References}

[1] J. M. Duncan, "State of the art: limit equilibrium and finiteelement analysis of slopes," Journal of Geotechnical and Geoenvironmental Engineering, vol. 122, no. 7, pp. 577-596, 1996.

[2] M. A. Biot, "General theory of three-dimensional consolidation," Journal of Applied Physics, vol. 12, no. 2, pp. 155-164, 1941.

[3] R. S. Sandhu and E. L. Wilson, "Finite element analysis of seepage in elastic media," Journal of the Engineering Mechanics Division, vol. 95, no. 3, pp. 641-652, 1969.

[4] J. T. Christian and J. W. Boehmer, "Plane strain consolidation by finite elements," Journal of Soil Mechanics \& Foundations Division, vol. 96, no. 4, pp. 1435-1457, 1970.

[5] J. M. Duncan and C.-Y. Chang, "Nonlinear analysis of stress and strain in soils," Journal of the Soil Mechanics and Foundations Division, vol. 96, no. 5, pp. 1629-1653, 1970.

[6] J. M. Duncan, P. M. Byrne, K. S. Wong, and P. Mabry, "Strength, stress-strain and bulk modulus parameters for finite element analyses of stresses and movements in soil masses," Tech. Rep. UCB/GT/80-01, University of California, Berkeley, Calif, USA, 1980.

[7] D. C. Drucker, R. E. Gibson, and D. J. Henkel, "Soil mechanics and work-hardening theories of plasticity," Transactions of the American Society of Civil Engineers, vol. 122, pp. 338-346, 1957.

[8] K. Roscoe, A. Schofield, and C. Wroth, "On the yielding of soils," Geotechnique, vol. 8, no. 1, pp. 22-53, 1958.

[9] K. Roscoe, A. Schofield, and A. Thurairajah, "Yielding of clays in states wetter than critical," Geotechnique, vol. 13, no. 3, pp. 211-240, 1963.

[10] J. Burland, "Correspondence on 'The yielding and dilation of clay"' Geotechnique, vol. 15, pp. 211-214, 1965.
[11] P. V. Lade and J. M. Duncan, "Elastoplastic stress-strain theory for cohesionless soil," Journal of the Geotechnical Engineering Division, vol. 101, no. 10, pp. 1037-1053, 1975.

[12] I. S. Sandler, F. L. DiMaggio, and G. Y. Baladi, "Generalized cap model for geological materials," Journal of the Geotechnical Engineering Division, vol. 102, no. 7, pp. 683-699, 1976.

[13] X.-S. Li, Y. F. Dafalias, and Z.-L. Wang, "State-dependent dilatancy in critical-state constitutive modelling of sand," Canadian Geotechnical Journal, vol. 36, no. 4, pp. 599-611, 1999.

[14] Y.-P. Yao and D. Sun, "Application of Lade's criterion to Camclay model," Journal of Engineering Mechanics, vol. 126, no. 1, pp. 112-119, 2000.

[15] G. Y. Baladi and B. Rohani, "Elastic-plastic model for saturated sand," Journal of the Geotechnical Engineering Division, vol. 105, no. 4, pp. 465-480, 1979.

[16] O. Zienkiewicz and Z. Mroz, "Generalized plasticity formulation and applications to geomechanics," in Mechanics of Engineering Materials, C. S. Desai and R. H. Gallagher, Eds., pp. 655-679, John Wiley \& Sons, New York, NY, USA, 1984.

[17] C. S. Desai and M. O. Faruque, "Constitutive model for geological materials," Journal of Engineering Mechanics, vol. 110, no. 9, pp. 1391-1408, 1984.

[18] S. B. R. Murthy, A. Vatsala, and T. S. Nagaraj, "Revised Camclay model," Journal of Geotechnical Engineering, vol. 117, no. 6, pp. 851-871, 1991.

[19] M. Pastor, O. C. Zienkiewicz, and A. H. C. Chan, "Generalized plasticity and the modelling of soil behaviour," International Journal for Numerical \& Analytical Methods in Geomechanics, vol. 14, no. 3, pp. 151-190, 1990.

[20] Z. Mroz and O. Zienkiewicz, "Uniform formulation of constitutive equations for clays and sands," in Mechanics of Engineering Materials, C. S. Desai and R. H. Gallangher, Eds., pp. 415-449, John Wiley \& Sons, New York, NY, USA, 1984.

[21] G. Wang and J.-M. Zhang, "Dynamic consolidation finite element analysis of a sediment-protecting dyke under ocean wave loading," Rock and Soil Mechanics, vol. 27, no. 4, pp. 555560, 2006.

[22] M. Alyami, M. Rouainia, and S. M. Wilkinson, "Numerical analysis of deformation behaviour of quay walls under earthquake loading," Soil Dynamics and Earthquake Engineering, vol. 29, no. 3, pp. 525-536, 2009.

[23] H. Li, P. Manuel, and T. Li, "Application of an generalized plasticity model to ultra-high rockfill dam," in Proceedings of the 12th International Conference on Engineering, Science, Construction, and Operations in Challenging EnvironmentsEarth and Space, pp. 385-398, Honolulu, Hawaii, USA, March 2010.

[24] T. Li and H. Zhang, "Dynamic parameter verification of P$\mathrm{Z}$ model and its application of dynamic analysis on rockfill dam," in Proceedings of the 12th International Conference on Engineering, Science, Construction, and Operations in Challenging Environments_Earth and Space, pp. 2706-2713, Honolulu, Hawaii, USA, March 2010.

[25] M. Pastor, "A generalized plasticity model for anisotropic behaviour of sand," Computer Methods and Advances in Geomechanics, vol. 1, pp. 661-668, 1991.

[26] G. Bolzon, B. A. Schrefler, and O. C. Zienkiewicz, "Elastoplastic soil constitutive laws generalized to partially saturated states," Geotechnique, vol. 46, no. 2, pp. 279-289, 1996.

[27] H. I. Ling and H. Liu, "Pressure-level dependency and densification behavior of sand through generalized plasticity model," 
Journal of Engineering Mechanics, vol. 129, no. 8, pp. 851-860, 2003.

[28] H. I. Ling and S. Yang, "Unified sand model based on the critical state and generalized plasticity," Journal of Engineering Mechanics, vol. 132, no. 12, pp. 1380-1391, 2006.

[29] N. D. Marschi, C. K. Chan, and H. B. Seed, "Evaluation of properties of rockfill materials," Journal of the Soil Mechanics and Foundations Division, vol. 98, no. 1, pp. 95-114, 1972.

[30] R. J. Marsal, "Large scale testing of rockfill materials," Journal of the Soil Mechanics and Foundations Division, vol. 93, no. 2, pp. 27-43, 1967.

[31] R. J. Marsal, "Mechanical properties of rockfill," in Embankment Dam Engineering, pp. 109-200, John Wiley \& Sons, New York, NY, USA, 1973.

[32] P. V. Lade, J. A. Yamamuro, and P. A. Bopp, "Significance of particle crushing in granular materials," Journal of Geotechnical and Geoenvironmental Engineering, vol. 122, no. 4, pp. 309-316, 1996.

[33] B. O. Hardin, “Crushing of soil particles," Journal of Geotechnical Engineering, vol. 111, no. 10, pp. 1177-1192, 1985.

[34] R. L. Kondner, "Hyperbolic stress-strain response: cohesive soils," Journal of the Soil Mechanics and Foundations Division, vol. 89, no. 1, pp. 115-143, 1963.

[35] Z.-L. Wang, Y. F. Dafalias, X.-S. Li, and F. I. Makdisi, "State pressure index for modeling sand behavior," Journal of Geotechnical and Geoenvironmental Engineering, vol. 128, no. 6, pp. 511-519, 2002. 


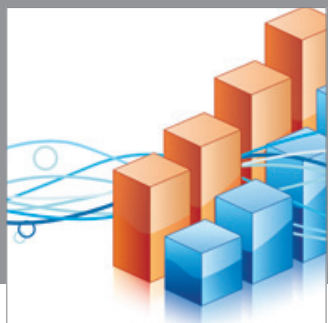

Advances in

Operations Research

mansans

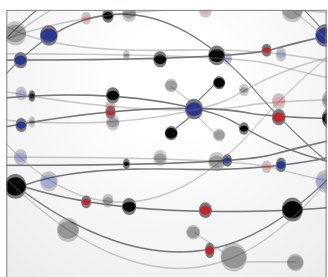

The Scientific World Journal
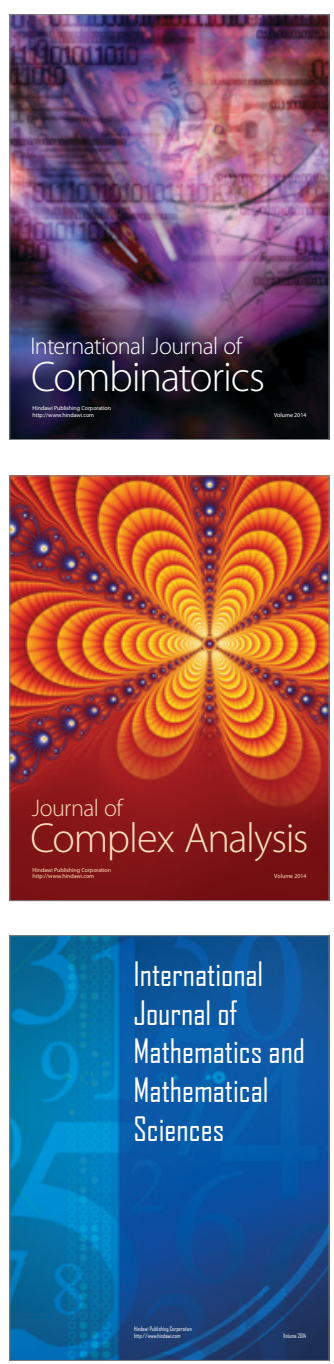
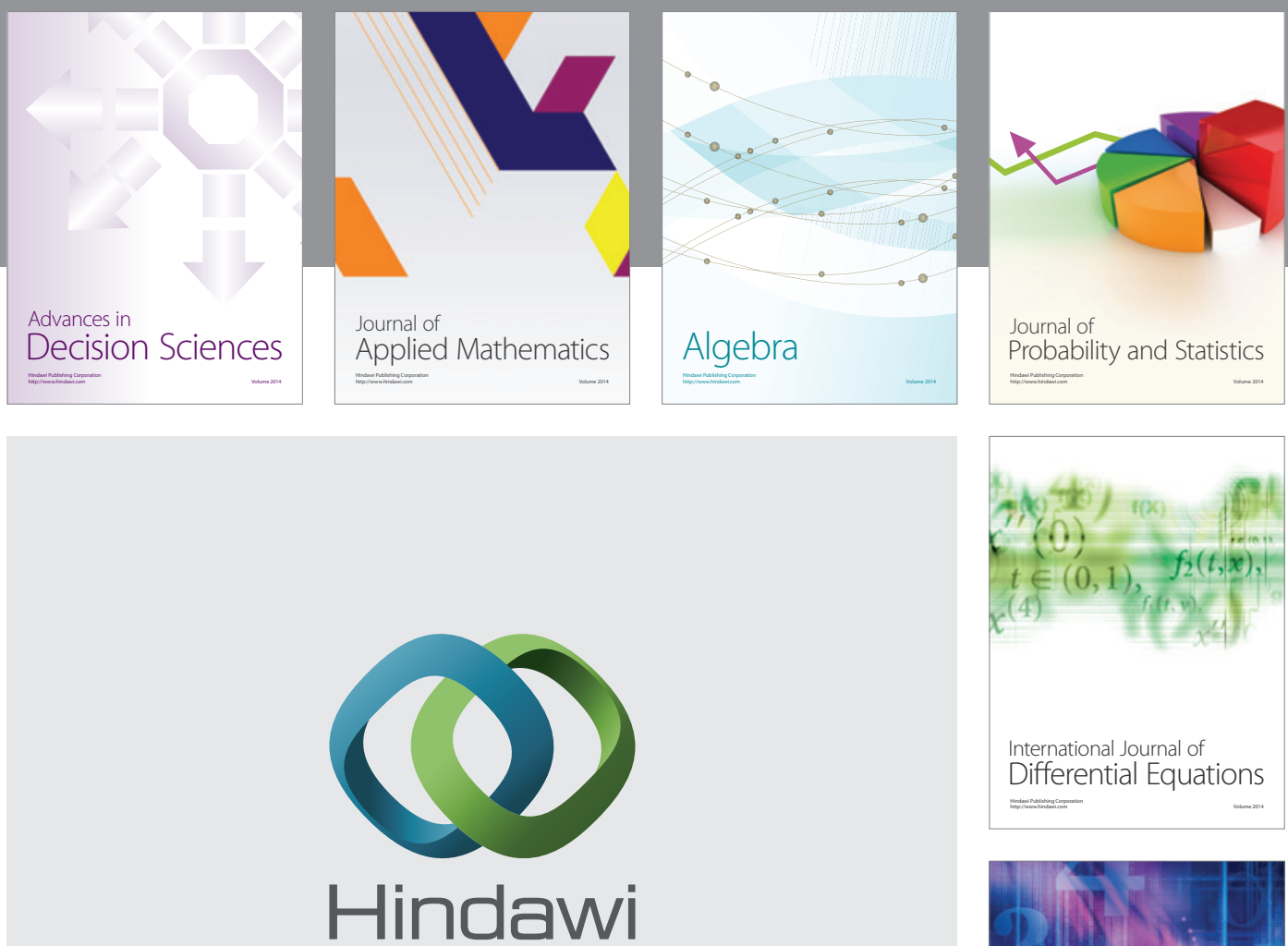

Submit your manuscripts at http://www.hindawi.com
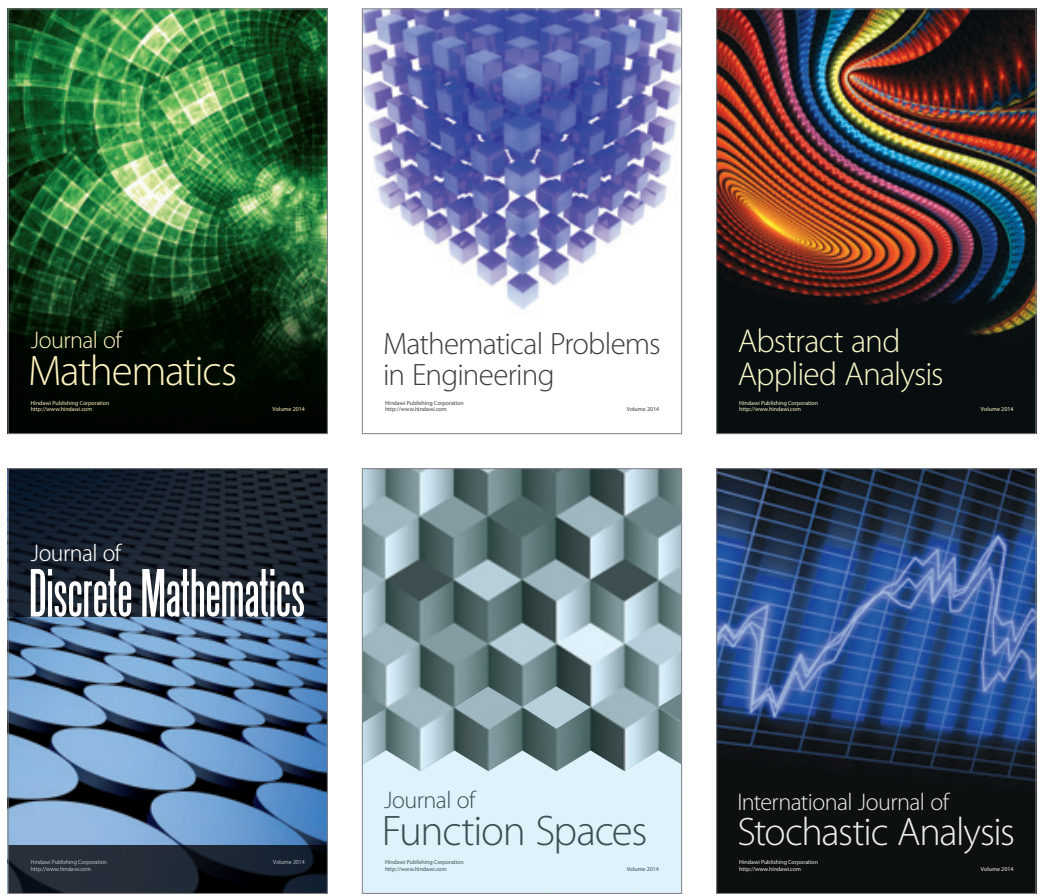

Journal of

Function Spaces

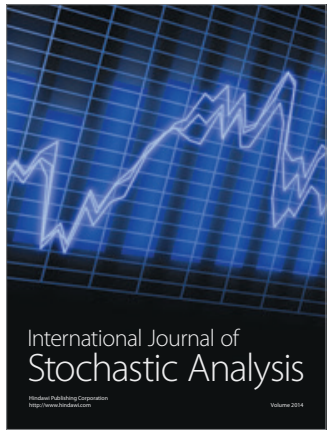

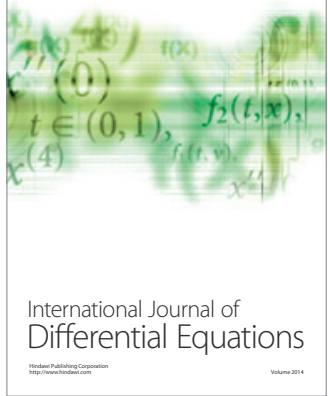
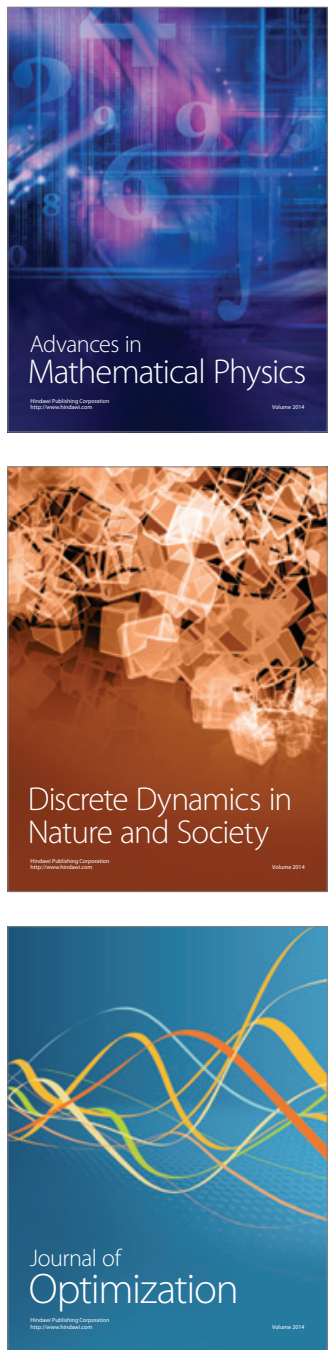